\title{
Haematopoiesis Stimulating Role of IL-12 \\ Enabling Bone Marrow Transplantation in Irradiated Rats
}

\author{
O. M. Ashry, M. El Shahat*, I. Abou el Khier* and H. Abd \\ el Sammad
}

Radiation Biology Dept., National Centre for Radiation Research and Technology (NCRRT), P. O. Box: 29 Nasr City, Cairo, Egypt. and "Genetic Engineering Institute, Monofia University.

QEVERE MYELOSUPPRESSION is a common side effect $\checkmark$ of radiotherapy or chemotherapy. As a mean to stimulate the full-lineage blood cell recovery from severe myeloid suppression, sub lethally irradiated animals were used to evaluate immunological effect of interleukin (IL-12) in bone marrow (BM) transplanted animals.

Isologous BM from the same inbred strain, were given to male rats, $1 \mathrm{~h}$ post whole body gamma irradiation at a single dose level of 5Gy and subcutaneous injection of $100 \mathrm{ng} / \mathrm{ml} \mathrm{IL-}$ 12. Irradiation induced a significant drop in haematological values, blood glutathione (GSH) as well as BM viability associated with a significant elevation of serum malondialdehyde (MDA). Related to immunological data, tumor necrosis factor alpha (TNF- $\alpha$ ) and interleukin 6 (IL-6) also recorded a significant depression.

Irradiated animals receiving BM and IL-12 showed significantly elevated body and spleen weights, erythrocytes count (RBCs), haemoglobin content $(\mathrm{Hb})$ and haematocrit value (Hct\%) besides, white blood cells (WBCs) and its differential count, as well as GSH, while MDA was significantly depressed as compared to the irradiated group. BM viability was significantly increased while IL-6 and TNF- $\alpha$ were normalized.

The curative action of IL-12 enforcing significant innate response could trigger and augment adaptive immune response by $\mathrm{BM}$ transplantation, hence improving oxidative stress. IL-12 administration is proposed as a complementary strategy to treat radiation-induced path-physiology and tripping free radicals accumulations after irradiation.

Keywords: Irradiation, bone marrow transplantation, interleukin-12, rats. 
Acute effects of radiation include hematopoietic cell loss, immune suppression, and potential injury to other sites such as the lung, kidney and central nervous system (Augustine et al. 2005). Irradiation ruptures adult tissue homeostasis, inducing radiation syndromes, described in hematopoietic tissue (for doses higher than $2 \mathrm{~Gy}$, total body irradiation). It appears that a major mechanism of these syndromes is a rapid and massive cell death in stem and/ or progenitor cell populations, which can follow either apoptotic or necrotic pathways (Harfouche and Martin, 2010).

Haematopoietic cell transplantation holds promise as a potential treatment for victims of radiation exposure. Combining agents or treatments as immune regulatory factors enabling BMT rather than single therapeutic agent is a therapy of choice (Augustine et al., 2005). Activated human lymphocytes produce various colony stimulating factors that regulate proliferation and maturation of haematopoietic progenitor cells and modulate function of mature cells, thereby playing an important role in regulating inflammatory responses vital to host defence (Weisbart and Gold, 1989). IL-12 is a heterodimeric proinflammatory cytokine that regulates the activity of cells involved in the immune response (Zeh et al., 1993). It stimulates the production of IFN- $\gamma$ from natural killer cells and $\mathrm{T}$ cells, favours the differentiation of $\mathrm{T}$ helper-1 cells, and forms a link between innate resistance and adaptive immunity (Ploemacher et al., 1993). IL-12 provides broad-spectrum protection after irradiation by stimulating the proliferation of residual haematopoietic progenitor cells and the reconstitution of neutrophil, monocyte, erythrocyte and platelet population (Colombo and Trinchieri, 2002).

The innate immune system, which uses numerous receptors, cytokines and chemokines, can respond immediately and stimulation of signal receptors can trigger the production and release of cytokines (Zhang et al., 2000). Preclinical and clinical studies demonstrated that a broad range of cytokines can serve to accelerate BM, adaptive immune responses, restoration following myeloid ablative cytotoxic drugs or radiation, i.e. a significant innate response can trigger and augment adaptive immune responses (Miller and Neta 1993). This work aims to assess the role of one of a hematopoietic stem cell supportive cytokine,IL-12, on early haematopoietic reconstitution and engraftment of BM transplanted cells as well as suppression of oxidative stress 14 days post 5Gy whole body gamma irradiation.

Egypt. J. Rad. Sci. Applic., Vol. 24, No. 2 (2011) 


\section{Material and Methods}

Mature male albino rats of pure strain (Rattus albinus) ranging from 110$130 \mathrm{~g}$ body wt were obtained from the animal house of the NCRRT, Cairo, Egypt. The animals were maintained on a commercial standard pellet diet and tap water ad libitum.

Radiation facility; whole body $\gamma$-irradiation was performed with a Canadian ${ }^{137}$ Cs Gamma Cell-40 biological irradiator located at NCRRT, Cairo, Egypt, at a dose rate of $0.44 \mathrm{~Gy} / \mathrm{min}$. The unit has ventilation holes which align with ventilation parts through the main shield to provide a means for uniform irradiation for experimental animals. Rats were exposed to whole body $\gamma$ radiations delivered as an acute dose of $5 \mathrm{~Gy}$.

Isologous transplantation; donors and recipients were chosen of the same inbred strain, brother to brother (allogenic transplantation). BM suspension: Femur bones of donors were dissected out and cleaned and the marrow was blown out into $5 \mathrm{ml}$ ice cold saline solution, pooled and mixed by drawing and expelling it several times from the syringe without needle to avoid mechanical damage. $75 \times 10^{6} \pm 5$ bone marrow cells (BMT) were injected (iv) into the caudal vein1 h after irradiation of rats (Decleave et al., 1972).

Administration of Interlukine-12: Recombinant rat IL-12 with a molecular wt of $70 \mathrm{kD}$ was purchased from KOMA BIOTECH INC, UK. The vial was briefly centrifuged prior to opening and was dissolved in phosphate-buffered saline (PBS) at $100 \mathrm{ng} / \mathrm{ml}$ stock concentration according to (Chen et al., 2007).

Groups of Animals; rats were categorized into 7 groups each of 6 rats: Control group. Rats injected with BMT $\left(75 \times 10^{6}\right)$ cells through the caudal vein $\left(\mathrm{C}_{\mathrm{BM}}\right)$. Rats injected iv with $100 \mathrm{ng} / \mathrm{ml}$ of IL-12 $\left(\mathrm{C}_{\mathrm{IL}-12}\right)$. Rats exposed to $5 \mathrm{~Gy}$ whole body gamma irradiation (R). Group of rats exposed to $5 \mathrm{~Gy}$ gamma rays and received BMT, one $h$ after irradiation $(\mathrm{R}+\mathrm{BM})$. Irradiated animals injected i.v. with a single dose of $100 \mathrm{ng} / \mathrm{ml}$ of IL-12, one h after irradiation (R+ IL-12). Irradiated animals treated with BMT and injected with IL-12, one $\mathrm{h}$ after irradiation (R+ BM+ IL-12). All animals groups were sacrificed after 14 days.

Collection of samples: After 14 days, body wt was determined, then animals were lightly anesthetized and two blood samples were immediately

Egypt. J. Rad. Sci. Applic., Vol. 24, No. 2 (2011) 
collected by heart puncture. Part of the blood was placed on EDTA for haematological assays. The blood sample was used to determine blood GSH and the rest was centrifuged (1000 $\mathrm{xg}$ for $10 \mathrm{~min})$. Serum was collected in test tubes with screw caps and stored at $-20{ }^{\circ} \mathrm{C}$ until analysed. The spleen, was dissected out, weighed, washed in saline and dried on filter paper. A known wt of the spleen was homogenized in $0.15 \mathrm{M} \mathrm{KCl}$ to obtain a $10 \%$ tissue homogenate. Femur bones were dissected out and cleaned and the BM was blown out. A uniform cell suspension of BM was prepared by dilution in saline solution. BM film was prepared on a microscope slide and stained using trypan blue, where only dead cells absorbed the dye, all the cells were counted on a haemocytometer (Goldberg et al., 1992). \% viability= viable cells/total No. per femur X 100.

Haematological analysis; RBCs, WBCs counts were performed in a haemocytometer using standard procedures, Hct \% was determined according to Dacie and Lewis (1993) and Hb content according to Carl and Braun (2005). Physiological parameters; blood GSH was measured by the method of Beutler, et al. (1963) and spleen MDA was estimated according to Ohkhawa et al. (1979). IL-6 Eliza kit was obtained from Kamya Biomedical Company Gateway Seatle, USA and measured according to Medzhitov (2001) and TNF- $\alpha$ concentration was determined by kit from Proassay and was measured according to Aramachi (1989).

Statistical analysis; Results are expressed as means \pm SEM (standard error of mean). Comparisons among groups $(n=8)$ were performed by one-way analysis of variance (ANOVA) followed by the Tukey's post-test; differences were considered statistically significant at $P<0.05$ according to Steel and Tosrie (1980).

\section{Results}

Results in Table 1. indicate no significant change in mean body wt as well as spleen wt by IL-12 or BMT treatment. Radiation exposure induced significant drop in both body and spleen wt. Irradiation combined by BMT or IL-12 treatment showed no significant change in body and spleen wt. Irradiated animals treated with BMT and IL-12 administration attained elevated body and spleen wt approaching the control group after 14 days. BM viability in normal rats was $76.13 \pm 1.45 \%$ per femur. BM viability was significantly decreased in

Egypt. J. Rad. Sci. Applic., Vol. 24, No. 2 (2011) 
irradiated animals to $68.01 \pm 1.30 \%$. However, accelerated BM reconstitution was observed after BMT or IL-12 treatment to irradiated animals showing significant elevation $(P<0.05)$ above the irradiated group, whereas combined treatments to irradiated animals normalized viable BM cells.

TABLE 1. Effect of BMT and IL-12 on body and spleen wt and percentage changes of viable BM count $\%$ of irradiated and non-irradiated rats.

\begin{tabular}{|l|c|c|c|}
\hline \multicolumn{1}{|c|}{ Groups } & Body (wt) & Spleen $(w t)$ & Viable BM count (\%) \\
\hline Control & $130.50 \pm 1.88$ & $0.81 \pm 0.12$ & $76.13 \pm 1.45$ \\
\hline CBM & $128.67 \pm 2.63$ & $0.37 \pm 0.07$ & $73.84 \pm 1.13$ \\
\hline IL-12 & $128.17 \pm 1.82$ & $0.72 \pm 0.03$ & $75.80 \pm 0.71$ \\
\hline R & $120.83 \pm 1.33 \mathrm{c}$ & $0.48 \pm 0.39 \mathrm{c}$ & $68.01 \pm 1.30 \mathrm{c}$ \\
\hline R+ BM & $124.17 \pm 1.35 \mathrm{c}$ & $0.56 \pm 0.04 \mathrm{c}$ & $72.0 \pm 0.96 \mathrm{cr}$ \\
\hline R+ IL-12 & $122.83 \pm 1.08 \mathrm{c}$ & $0.53 \pm 0.04 \mathrm{c}$ & $71.28 \pm 0.91 \mathrm{cr}$ \\
\hline R+ BMT+ IL-12 & $127.8 \pm 2.50 \mathrm{r}$ & $0.71 \pm 0.09 \mathrm{r}$ & $75.15 \pm 0.43 \mathrm{r}$ \\
\hline
\end{tabular}

Values are expressed as mean \pm S.E.

c: Significant difference compared to control. r: Significant difference compared to R.

Table 2. discerned no changes in peripheral blood parameters compared to the control by BMT or IL-12 treatment, after 14 days in non-irradiated rats. Animals irradiation at 5Gy induced significant depressions $(P<0.05)$ of RBCs and WBCs count, $\mathrm{Hb}$ content and $\mathrm{Hct} \%$. This depression was significantly elevated in irradiated animals treated with BM or IL-12 compared to the irradiated group and was alleviated after the combination treatment with BMT and IL-12.

TABLE 2. Effect of BMT and IL-12 administration on blood parameters of irradiated and non-irradiated rats.

\begin{tabular}{|l|c|c|c|c|}
\hline \multicolumn{1}{|c|}{ Groups } & Hct $(\%)$ & Hb $(\mathrm{g} / \mathrm{dl})$ & RBCs $\left(10^{6} / \mathrm{mm}^{3}\right)$ & WBCs $\left(10^{3} / \mathrm{mm}^{3}\right)$ \\
\hline Control & $50.10 \pm 3.98$ & $13.76 \pm 0.39$ & $5.73 \pm 0.16$ & $10.71 \pm 0.22$ \\
\hline CBM & $49.07 \pm 2.11 \mathrm{r}$ & $12.85 \pm 0.65 \mathrm{r}$ & $5.35 \pm 0.27 \mathrm{r}$ & $9.67 \pm 0.82 \mathrm{r}$ \\
\hline IL-12 & $49.18 \pm 1.09 \mathrm{r}$ & $13.05 \pm 0.25 \mathrm{r}$ & $5.44 \pm 0.10 \mathrm{r}$ & $10.30 \pm 0.29$ \\
\hline R & $27.11 \pm 3.02 \mathrm{c}$ & $5.38 \pm 1.53 \mathrm{c}$ & $2.25 \pm 0.64 \mathrm{c}$ & $4.51 \pm 0.13 \mathrm{c}$ \\
\hline R+ BM & $36.57 \pm 1.55 \mathrm{cr}$ & $8.83 \pm 0.78 \mathrm{cr}$ & $3.68 \pm 0.32 \mathrm{cr}$ & $7.54 \pm 0.37 \mathrm{r}$ \\
\hline R+ IL-12 & $42.88 \pm 2.89 \mathrm{r}$ & $8.48 \pm 1.50 \mathrm{cr}$ & $3.12 \pm 0.67 \mathrm{cr}$ & $8.20 \pm 0.27 \mathrm{r}$ \\
\hline R+ BMT+ IL-12 & $48.79 \pm 1.91 \mathrm{r}$ & $11.38 \pm 0.14 \mathrm{r}$ & $4.74 \pm 0.06 \mathrm{r}$ & $9.30 \pm 0.92 \mathrm{r}$ \\
\hline
\end{tabular}

Legends as in Table1.

Results presented in Table 3. demonstrated that BMT or IL-12 treatment induced no change in differential leukocytes as compared to control. Significant reductions were recorded in lymphocytes, monocytes and neutrophils 14 days post-exposure to 5Gy gamma rays. BMT together with

Egypt. J. Rad. Sci. Applic., Vol. 24, No. 2 (2011) 
irradiation ameliorated the reduction induced by irradiation in the given parameters. IL-12 together with irradiation normalized lymphocytic count. Dual treatments induced significant elevation in lymphocytes, monocytes and neutrophil percentage compared to irradiated group to reach nearly the control.

TABLE 3. Effect of BMT and IL-12 administration on differential leukocyte and viable BM count $\%$ of irradiated and non-irradiated rats.

\begin{tabular}{|l|c|c|c|}
\hline \multicolumn{1}{|c|}{ Groups } & Lymphocytes (\%) & Monocytes (\%) & Neutrophils (\%) \\
\hline Control & $57.67 \pm 2.17$ & $5.67 \pm 0.76$ & $32.83 \pm 2.02$ \\
\hline CBM & $55.0 \pm 5.2$ & $4.5 \pm 0.50$ & $31.0 \pm 1.73 \mathrm{r}$ \\
\hline IL-12 & $58.67 \pm 3.60 \mathrm{r}$ & $5.33 \pm 0.84 \mathrm{r}$ & $26.50 \pm 2.13 \mathrm{r}$ \\
\hline R & $46.0 \pm 1.65 \mathrm{c}$ & $3.17 \pm 0.31 \mathrm{c}$ & $17.50 \pm 2.38 \mathrm{c}$ \\
\hline R+ BM & $47.33 \pm 2.67 \mathrm{c}$ & $3.83 \pm 0.48 \mathrm{c}$ & $19.83 \pm 1.94 \mathrm{c}$ \\
\hline R+ IL-12 & $54.17 \pm 2.39$ & $4.0 \pm 0.37 \mathrm{c}$ & $22.33 \pm 1.69 \mathrm{c}$ \\
\hline R+ BMT+ IL-12 & $59.67 \pm 4.81 \mathrm{r}$ & $5.83 \pm 0.48 \mathrm{r}$ & $28.50 \pm 3.37 \mathrm{r}$ \\
\hline
\end{tabular}

Legends as in Table1.

Results presented in Table 4. indicate that BMT or IL-12 treatment induced no change in blood GSH and serum MDA. A significant $(P<0.05)$ decrease was observed in blood GSH, while a significant elevation was detected in serum MDA, 14 days post exposure to 5Gy gamma radiation. BMT or IL-12 treatment to irradiated animals ameliorated GSH content and depressed MDA significantly compared to the irradiated group. Dual treatments normalized both GSH and MDA showing significant differences compared to irradiated group.

TABLE 4. Effect of BMT and IL-12 administration on blood GSH and serum MDA of irradiated and non-irradiated rats.

\begin{tabular}{|l|c|c|}
\hline \multicolumn{1}{|c|}{ Groups } & GSH $(\mathrm{mg} / \mathrm{ml})$ & MDA $(\mu \mathrm{mol} / \mathrm{ml})$ \\
\hline Control & $42.61 \pm 3.64$ & $60.33 \pm 3.27$ \\
\hline CBM & $39.74 \pm 2.77 \mathrm{r}$ & $61.89 \pm 1.87 \mathrm{r}$ \\
\hline IL-12 & $39.88 \pm 3.64 \mathrm{r}$ & $62.22 \pm 3.05 \mathrm{r}$ \\
\hline R & $30.10 \pm 2.53 \mathrm{c}$ & $111.89 \pm 7.02 \mathrm{c}$ \\
\hline R+ BM & $32.08 \pm 4.70 \mathrm{c}$ & $78.22 \pm 3.47 \mathrm{cr}$ \\
\hline R+ IL-12 & $35.30 \pm 2.72 \mathrm{c}$ & $82.11 \pm 1.39 \mathrm{cr}$ \\
\hline R+ BMT+ IL-12 & $39.40 \pm 1.71 \mathrm{r}$ & $64.45 \pm 4.04 \mathrm{r}$ \\
\hline
\end{tabular}

Legends as in Table1.

BMT alone and IL-12 alone did not induce any significant change in IL-6 or TNF- $\alpha$ as compared to control group. A significant $(P<0.05)$ decrease was obtained in serum IL- 6 and TNF- $\alpha$ value, 14 days post 5 Gy gamma irradiation compared to the control group. No significant increase $(P<0.05)$ was detected

Egypt. J. Rad. Sci. Applic., Vol. 24, No. 2 (2011) 
in IL- 6 of irradiated rats treated with BMT or with IL-12 compared to the irradiated group, while a significant elevation was detected for TNF- $\alpha$.

TABLE 5. Effect of BMT and II-12 administration on IL-2 and TNF- $\alpha$ of irradiated and non-irradiated rats.

\begin{tabular}{|l|c|c|}
\hline \multicolumn{1}{|c|}{ Groups } & IL-6 $(\mathrm{pg} / \mathrm{ml})$ & TNF- $\boldsymbol{\alpha}(\mathrm{pg} / \mathrm{ml})$ \\
\hline Control & $141.48 \pm 4.42$ & $22.5 \pm 0.22$ \\
\hline CBM & $140.51 \pm 2.91$ & $21.17 \pm 1.95$ \\
\hline IL-12 & $139.42 \pm 3.57$ & $21.67 \pm 0.76$ \\
\hline R & $131.08 \pm 4.40 \mathrm{c}$ & $14.17 \pm 0.11 \mathrm{c}$ \\
\hline R+ BM & $136.96 \pm 2.71$ & $15.47 \pm 0.31 \mathrm{c}$ \\
\hline R+ IL-12 & $135.92 \pm 3.31$ & $17.03 \pm 1.31 \mathrm{c} \mathrm{r}$ \\
\hline R+ BMT+ IL-12 & $138.54 \pm 2.07 \mathrm{r}$ & $20.67 \pm 1.12 \mathrm{r}$ \\
\hline
\end{tabular}

Legends as in Table1.

Combined treatment post irradiation showed significant elevation in IL-6 and TNF- $\alpha$ compared to the irradiated group (Table 4).

\section{Discussion}

In the present investigation5 Gy gamma irradiation induced significant depression in viable BM count; this was attributed by Chen et al. (2007) to myeloid suppression as the BM is the most sensitive organ to ionizing radiation. Radiation exposure may cause BM suppression and depletion of peripheral blood lymphocytes (Dillman, 2006). RBCs, WBCs, differential leukocyte count, $\mathrm{Hb}$ and haematocrit were found to decrease significantly post-irradiation as compared to control values. This might be attributed to the interaction of ionizing radiation on RBCs that leads to loss of their integrity leading to haemolysis; it can be considered as an example of the interphase death of nondividing cells (koziczak et al., 1999). Nevertheless, the decrease in the haemoglobin content may be due to the decrease in the number of RBCs and/ or the leakage of RBCs besides depletion in the synthesis of $\mathrm{Hb}$ after radiation exposure. A depression in the haematocrit value can be attributed to total cell depletion in peripheral blood aided by disturbances in steady state mechanisms in blood forming organs as well as an increase in plasma volume after irradiation (Singh et al., 2011).

The fast decline in WBCs as revealed by differential leukocyte count was attributed by Samarth and kumar (2003) to their high radio sensitivity. The cellular elements of the blood are particularly sensitive to oxidative stress

Egypt. J. Rad. Sci. Applic., Vol. 24, No. 2 (2011) 
because their plasma membranes contain a high percentage of polyunsaturated fatty acids (Chew and Park, 2004). Therefore the decrease in white blood cells differential count recorded in the irradiated rats might be the consequence of radiation-induced lipid peroxidation and damage of their cell membranes. Whole body irradiation (5Gy) of animals induced significant drop in GSH and elevation in lipid peroxides. Decreased level of GSH is generally considered as an index of increased oxidative stress. It may indicate inability of the cells to generate enough GSH, due to severe cellular damage or due to greater utility in combating the oxidative stress (Uma Devi, 2001). Depletion in tissue GSH may be attributed in part to inflammation (Meister, 1991). Excessive lipid peroxidation can cause increased glutathione consumption (Manda and Bhatia, 2003).

The present results showed that $5 \mathrm{~Gy} \gamma$-irradiation induced a significant depression of IL- 6 and TNF- $\alpha$ after 14 days. IL- 6 is a multifunctional cytokine that regulates the immune response, acute phase reactions, and haematopoiesis (Hirano, 1992) and as an anti-inflammatory cytokine it has the ability to induce TNF- $\alpha$ production. Hence their significant drop was attributed by Le et al. (2010) to radiation-induced reduction in tissue functionality of the immune system. Irradiation suppresses TNF- $\alpha$ production through up regulation of MKP-1 in mouse macrophage (Tsukimoto et al., 2009). The immunosuppression caused by $\gamma$-irradiation was due to the differential regulation of the T-helper cell type 1 and T-helper cell type 2 cytokine gene expressions (Seon-Kyu et al., 2002).

The present significant elevation in haematological parameters after BMT compared to the irradiated group agrees with preclinical and clinical studies that demonstrated that bone marrow stromal cells (MSCs) can be used for tissue repair (Yoon et al., 2010). This observation is further supported by the increased BM viability. Total body irradiation followed by BMT has been shown to raise the erythropoietic activity in both BM and spleen (De Rooij et al., 2002), thus the elevation in red blood cells, the important source of GSH, can ameliorate GSH depletion in blood and organs and hence oxidative stress.

Leucocyte elevation was noted, while lymphocyte recovery was not detected during this time period in case of irradiated animals treated with BM, which might not result from failure of lymphocytes to respond, but from cell death. Lymphocytes have different rate of turnover, thus radiation dose rate could have a dramatic effect on phenotype distribution (Hall, 1994).

Egypt. J. Rad. Sci. Applic., Vol. 24, No. 2 (2011) 
BMT alone did not induce any significant change in IL- 6 or TNF- $\alpha$ as compared to control group which is related to absence of immunological reaction against non-HLA allogeneic antigens. It is generally known that IL-6 and TNF increase during the aplastic phase in most patients and is associated with several complications, such as GVHD or infectious episodes (Ferra, et al., 1998) which might explain the observed amelioration after irradiation and BMT. TNF may be produced as a result of latent infections or immunological reaction against non-HLA allogeneic antigens. This is supported by the experimental observation that TNF is produced in allogeneic mixed lymphocyte reaction (Shalaby et al., 1988). TNF- $\alpha$ regulates the effect of irradiation in mouse BM microenvironment (Cachaco et al., 2010). Furthermore, neutralization of TNF- $\alpha$ have been reported by Brown and Thiele (2000) to reduce complications after BMT.

The present findings showed no significant difference in body wt whereas, accelerated BM and haematopoietic reconstitution were observed between the control and irradiated animals treated with IL-12. It is well known that low dose of IL-12 has hematopoietic-protecting effects, which can attenuate severe myeloid suppression caused by irradiation (Chen et al., 2007). The present findings demonstrated reduction of oxidative damage attributed to IL-12stimulatory effect on haematopoiesis recovery of a full- lineage blood cell production, including white and red blood cells the important source of GSH, (Chen et al., 2007).

IL-12 can protect BM haematopoietic system and hence synthesis and release of endogenous haematopoietic regulatory cytokines (Chirigos et al., 1985). The radio protective effect of IL-12 have immerged from reduction of oxidative damage through induction of scavenging proteins as IL-6 which plays a role together with TNF in innate defence against ionizing radiation (Neta,1996). Irradiated animals treated with BMT and IL-12 administration attained elevated body and spleen weights approaching the control group after 14 days, as well as accelerated BM reconstitution showing normal viable BMT. This was reflected upon accelerated haematopoietic reconstitution and depressed oxidative stress. IL-12 promotes engraftment in BMT by affecting the cells in the BM microenvironment (Chen et al., 2007). Radio protective effect of IL-12 has immerged from reduction of oxidative damage enhancing the role played by IL-6 and TNF in innate defence against ionizing radiation (Neta, 1996).

Egypt. J. Rad. Sci. Applic., Vol. 24, No. 2 (2011) 
The study demonstrated that IL- 12 may foster BM transplantation and promote recovery of haematopoiesis. It enhances biological defence activities against oxidative stress by boosting adaptive and innate immunity. It raises the possibility of using IL-12 as an adjuvant therapy to enhance the recovery of endogenous haematopoiesis after irradiation or chemotherapy to facilitate engraftment of stem cells in BMT.

\section{References}

Aramachi, T. (1989) Immunono-Biological Laboratories Company, Ltd. Japan, pp. 370- 381.

Augustine, A. D., Gondre-Lewis, T., McBride, W., Miller, L., Pellmarc, T. C. and Rockwelld, S. (2005) Animal models for radiation injury, protection and therapy. Rad. Res., 164, 100.

Beutler, E., Duron, O. and Kelly, B. (1963) Improved method for determination of blood glutathione. Lab. Clin. Med., 61, 5 .

Brown, G. and Thiele, D. (2000) Enhancement of MHC class I-stimulated alloresponses by TNF/TNF receptor (TNFR) 1 interactions and of MHC class II-stimulated alloresponses by TNF/TNFR2 interactions. Eur. J. Immunol., 30, 2900.

Cachaço, A. S., Carvalho, T., Santos, A. C., Igreja, C. and Fragoso R. (2010) TNF- $\alpha$ regulates the effects of irradiation in the mouse bone marrow microenvironment. Rad. Res., 5, 8980.

Carl, A. and Braun, C. (2005) Tietz Textbook of Clinical Chemistry and Molecular Biology. 2nd ed. Saunders Company p. 566.

Chen, T., Burke, K., Zhan, Y., Wang, X., Shibata, D. and Zhao, Yi. (2007) IL-12 Facilitates both the recovery of endogenous hematopoiesis and the engraftment of stem cells after ionizing radiation. Exp. Hematol., 35, 203.

Chew, B. and Park, J. (2004) Carotenoid action on the immune response. J. Nutr., 134, $257 \mathrm{~S}$

Chirigos, M., Saito, T., Schlich, E. and Ruthman, R. (1985) Cellular regulation by immunomodifiers MVE-2 and poly-ICLC and their therapeutic application. Cancer application. Cancer Treat. Symp.1, 11.

Colombo, A. and Trinchieri, E. (2002) Interleukin-12 in anti-tumor immunity and immunotherapy. Cytokine \& Growth Factor Rev., 13, 155.

Dacie, S. T. and Lewis, S. M. (1993) Practical Haematology. ELBS and Churchill, Levingston. London Chapt. 5, p. 37.

Decleave, A., Gerber, G. B., Leonard, M., Lambiet-Collier, M., Sassen, A. and Maisin, J. R. (1972) Regeneration of thymus, spleen and bone marrow in Xirradiated AKR mice. Rad. Res., 51, 318.

Egypt. J. Rad. Sci. Applic., Vol. 24, No. 2 (2011) 
De Rooij, D. G., Van de Kant, H. J., Dol, R., Wagemaker, G. and Van Buul, P. P. (2002) Long-term effects of irradiation before adulthood on reproductive function in the male Rhesus monkey. Biol. Reprod. 66, 486.

Dillman, R. O. (2006) Radioimmunotherapy of B-cell lymphoma with radiolabelled anti-CD20 monoclonal antibodies. Clin. Exp. Med., 6, 1.

Ferra, C., de Sanjose, S. and Gallardo, D. (1998) IL-6 and IL-8 levels in plasma during hematopoietic progenitor transplantation. Haematologica, 83, 1082.

Goldberg, E. D., Dygal, A. M. and Shakhov, V. P. (1992) Methods for tissue culture in hematology; TGU Publishing House, Tomsk : 256.

Hall, E. J. (1994) Radiobiology for the radiologists. 4th ed., Philadelphia: LippincottRaven Pub.

Harfouche, G. and Martin, M. T. (2010) Response of normal stem cells to ionizing radiation: A balance between homeostasis and genomic stability. Review, Mut. Res., 704, 167.

Hirano, T. (1992) Interleukin-6 and its relation to inflammation and disease. Clin. Immunopathol., 62, Suppl. 1, S60.

Koziczak, R., Krokosz, A. and Szweda-lewandowska, Z. (1999) Effect of dose-rate and dose fractionation on radiation-induced hemolysis of human erythrocytes. Cell Mol. Biol., 47, 865.

Le, O., Rodier, F., Fontaine, F., Coppe, J., Campisi, J., DeGregori, J., Laverdière, C., Kokta, V., Haddad, E. and Beauséjour, C. (2010) Ionizing radiationinduced long-term expression of senescence markers in mice is independent of p53 and immune status. Aging Cell., 9, 398.

Manda, K. and Bhatia, A. L. (2003) Preadministration of beta-carotene protects tissue glutathione and lipid peroxidation status following exposure to gamma radiation. Environ. Biol., 24, 369.

Medzhitov, R. (2001) Toll-like receptors and innate immunity Nat. Rev., 1, 135.

Meister, A. (1991) Glutathione deficiency produced by inhibition of its syntheseis, and its reversal: Applications in research and therapy. Pharmacol. Ther., 51, 155.

Neta, R. (1996) Modulation with cytokines of radiation injury: Suggested mechanisms of action. Public Health Reviews, 24, 202.

Miller L. L. and Neta R. (1993) Therapeutic utility of cytokines in counteracting the bone marrow suppression of radio- and chemo-therapy. In: Clinical Applications of Cytokines: Role in Pathogenesis, Diagnosis and Therapy (Gearing A, Rossio J, Oppenheim JJ, eds). New York: Oxford University Press, p. 225.

Ohkhawa, H., Ohishi, N. and Yogi, K. (1979) Assay for lipid peroxidation in animal tissue by thiobarbituric acid reaction. Anal. Biochem., 95, 351.

Egypt. J. Rad. Sci. Applic., Vol. 24, No. 2 (2011) 
Ploemacher, R., van Soest, P., Voorwinden, H. and Boudewijn, A. (1993) Interleukin- 12 synergizes with interleukin-3 and steel factor to enhance recovery of murine hemopoietic stem cells in liquid culture. Leukemia, 7, 1381.

Samarth, R. M. and Kumar, A. (2003) Radioprotection of Swiss albino mice by plant extract Mentha piperita_(Linn). J. Radiat. Res., 44, 101.

Seon-Kyu, H., Jie-Young, S., Yeon-Sook, Y. and Seh-Yoon, Y. (2002) Gamma irradiation-reduced IFN-g expression, STAT1 signals, and cell-mediated immunity. J. Biochem. Mol. Biol., 35, 583.

Shalaby, M. R., Espevik, T., Rice, G. C., Ammann, A. J., Figari, I. S., Ranges, G. E. and Palladino, M. A. (1988) The involvement of human tumor necrosis factors- $\alpha$ and $\beta$ in the mixed lymphocyte reaction. J. Immunol. 141, 499.

Singh, A., Kumar, R., Nivedita, Singh, J. K. and Tanuj (2011) Radioprotective effect of Eclipta alba (L.) against radiation induced haematological changes in Swiss albino mice. J. Nat. Prod., 4, 177.

Steel, R .G. D and Tosrie , J. H. (1980) Analysis of covariance . In : Principles and Procedures of Statistical : A Biometrical Approach, 401.

Tsukimoto, M., Homma, T., Mutou, Y. and Kojima, S. (2009) 0.5Gy gamma radiation suppresses production of TNF-alpha through up-regulation of MKP-1 in mouse macrophage RAW264.7 cells. Radiat. Res. 17, 219.

Uma Devi, P. (2001) Radioprotective anticarcinogenic and antioxidant properties of the Indian holy basil, Ocimum Sanctum(tulsi). Indian J. Exp. Biol., 39, 185.

Weisbart, R. H. and Gold, D. W. (1989) Physiology of granulocyte and macrophage colony- stimulating factors in host defence. Hematol. Oncol. Clin. North Am., 3, 401 .

Youn, Yi, J., Jin Jang, Y., Shim Choi, S. and Chung, E. (2010) TNF-alpha down regulates E-cadherin and Sensitizes Response to $\gamma$-irradiation in Caco-2 Cells. Cancer Res. Treat., 41, 164.

Zeh, H., J3rd, Hurd, S., Storkus, W. J. and Lotze, M. T. (1993) Interleukin-12 promotes the proliferation and cytolytic maturation of immune effectors: implications for the immunotherapy of cancer. J Immunother., 14, 155.

Zhang, P., Summer, W. R., Bagby, G. J. and Nelson, S. (2000) Innate immunity and pulmonary host defense. Immunol.Rev., 173, 39.

(Received: 24/04/2012;

accepted: 11/06/2012)

Egypt. J. Rad. Sci. Applic., Vol. 24, No. 2 (2011) 


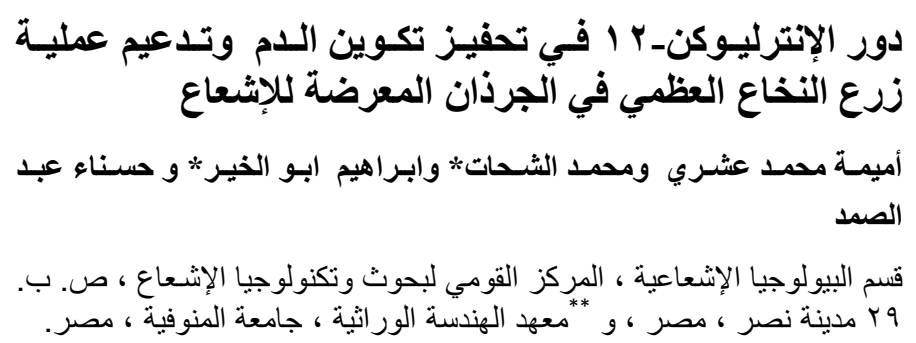

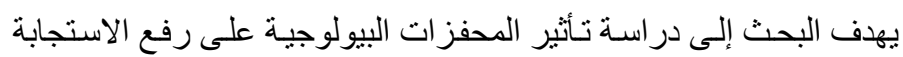

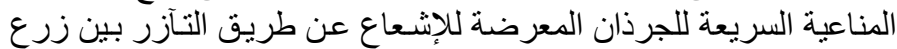

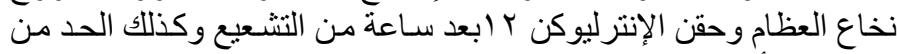

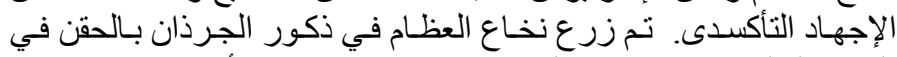

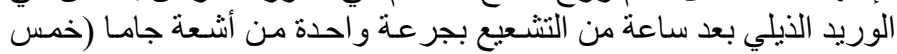

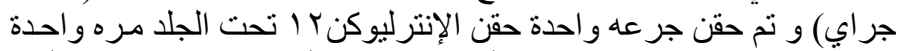

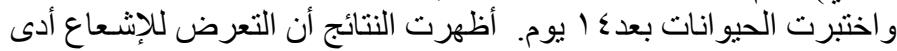

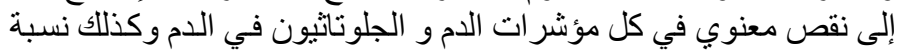

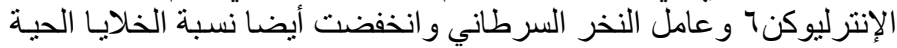

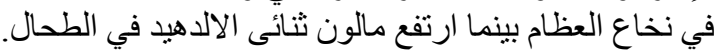

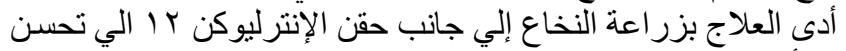

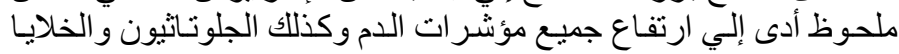

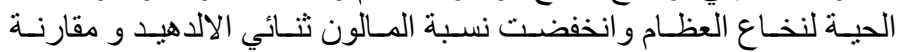

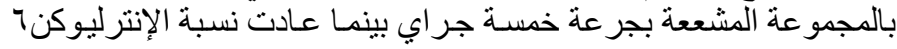
وعامل النخر السرطاني إلي نسبتهما الطبيعية.

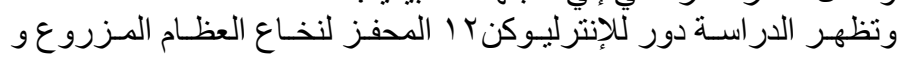

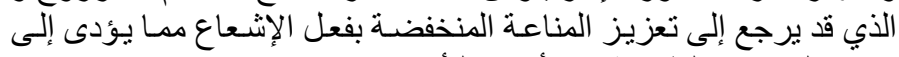
تحفيز الدفاعات الطبيعية ضد ألعبز أعناء التأكسد.

Egypt. J. Rad. Sci. Applic., Vol. 24, No. 2 (2011) 